included bits of text and images taking off from the Hopper.

Manuel Rocha Iturbide's recorded work Purusha-Prakrti, produced in Bourges, makes use of a number of noisy sources, both natural and electronic. I particularly enjoyed the fine transitions across the rich, sustained textures.

Members of Cincinnati's NeXT Ens convened once again for Yu-Chung Tseng's Reminiscence of Pipa for flute, percussion, and recorded sounds. Inspired by a Tang Dynasty-era poem, this was dramatic music. The composer showed a definite flair for the flute and percussion instruments. I otherwise found the music pretty predictable.

Jacob Rundall's This too shall pass... is an electroacoustic work based on analyses of bell and cymbal sounds. The music didn't make much of an impression on me; suppose it "passed" a bit too easily. It's all been done before, I suppose.

The concert concluded with an updated remix of Laurie Anderson's mega-hit from the early 1980s, O Superman. Joshua Clausen was joined by a couple of his (uncredited) colleagues from Minneapolis to perform live with their laptops. They got a nice groove going, and the video was cool, too. Imagine, tributes to Laurie and Jerry, all in one program!
ICMC 2007 Reviews

Aalborg University

Gopenhagen, Denmark

Esbjerg,

\section{Monday, 27 August}

17:00, PLEX Music Theatre

by Iowain Thomas

There could be no doubt that the concert was hot. An overflow crowd pressed forward, brandishing their hand-printed tickets at the bottom of the stairs leading to an elegant, steeply raked hall, where the temperature hovered around 30 degrees Celsius (hotter at the top). The less fortunate remained cooler in the cafe outside, speaking animatedly about (we may assume) the concert they were missing.

The overall form of the concert was (in pseudo-American parlance) a doubledecker Chowning sandwich on harp bread. This programming choice was both practical (the harp parts were substantial, so consecutive performances would have been unkind at best) and refreshing.

The combination of harp and electronics, while by no means novel, is nevertheless unusual. This is a pity. The relative consistency of the instrument's timbre is well complemented by the Protean world of disembodied sound, while the unusual constraints of the instrument itself can give direction to an electroacoustic composition in fascinating ways.

In some sense, Chowning's compositions on the program - particularly Stria - reflect a similar dichotomy between instrumental constraint and inventive freedom. After 30 years, Stria still astounds with its depth of exploration of a rigorously limited terrain. To elicit such musical range and force from a single compact harmonic/timbral structure and a single synthesis technique is no mean feat! Likewise, in Voices, Chowning relies on a simple event-driven scorefollowing model and a well-chosen palette of timbres and techniques. He treats the voice with dignity in elegant, almost bel canto vocal lines that leave ample room for nuanced interpretation. The imaginative room he finds within these boundaries vastly exceeds that of most works that are more technologically profligate.

Either it was the digital reconstruction of the work by Olivier Baudouin and Kevin Dahan, or else it was the Princeton Sound Lab's 3-D rendering of its spectrograph, but this writer heard elements in Stria that he had never noticed before, despite years of engagement with the work. The creators of the spectrograph video may have been more entrenched in video game culture than 
some of us; the sweeping, shifting point of view (occasionally ducking below the plane of the spectrogram) induced occasional seasickness (no, madam, I had not been drinking!). Nevertheless, on the balance of things it added to the experience.

Voices was inspiring. Maureen Chowning's performance was scintillating, and the electronic setting was subtle, sensitive, and spacious. Synthesis and spatialization were foremost in the sonic techniques of the work, creating an eerie and immersive sound world. The integration of timbre and harmony based on artificial scales within pseudo-octaves evoked the world of Stria from a distance. The serpentine hissing of vapors in the cave at Delphi, the frenzy of the oracle possessed by Apollo, the space between the internal vision and the cavernous space of the Pythia's templeall were represented and integrated into a deeply engaging and moving experience.

The drama and musicality of the work aside, how on earth is it that the guru of early digital synthesis has now become a master of the art of interactive music? While recognizing Chowning's unique mind and spirit, the author received new hope of being able to transcend his own current music technology armamentarium several decades hence!

Returning to the harp music: Robert Rowe, a more established master of interactivity, pulled out all the stops in Moon on the one side, Sun on the other. Inspired by an image in Marilynn Robinson's novel Gilead, the work's intensity reflects the notion of following two lights across the horizon as the moon rises and the sun sets. Swooping gestures and clouds of sound translate the harp timbre into an evocative soundscape. Gestures triggered by the harp take on their own shape and life. However, in some places the work might have benefited from greater independence between triggers and their responses.

Fausto Romitelli's Bad Trip Remix 1998 is inspired by the hallucinatory, drugfueled world of Henri Michaux. This Dionysian impulse results, strangely, in a well-ordered and Apollonian work: idiomatic harp gestures receive a delicate, well-crafted electroacoustic setting. The tape part continued in a long coda after the harp finished playing; the dramatic awkwardness of this raised the question of whether or not it was intentional. The intensity and conviction of Sofia Anunción Claro's playing tipped the balance toward the composer's culpability.

Ms. Claro seemed most at home in Kristine Burns's Nuance (Nuagein the program, but not on the composer's web site), a well-chosen ending to the concert. The conversation of harp and electroacoustic sound in this work spoke with a simpler, more direct language. Burns's composition seemed to lay especially well under the harpist's fingers (and feet), letting the instrument sing in its own voice. Alas, nearly overcome by the heat of the hall, some listeners may have been counting the minutes until they could again breathe the fresh air of Copenhagen's ancient cobbled streets.

\section{Tuesday, 28 August}

\section{2:00, School of Architecture}

by Mara Helmuth (final piece reviewed by Daichi Ando)

I will begin with some general comments. The lawn setting for the noon concert generally enhanced the presentation, giving an acoustically dry space. Occasional construction sounds sometimes led to confusion over whether the piece or real construction was being heard. Also, on the days that it rained, the umbrellas did not help in hearing the eight-channel diffusion. If there was a "front" and "back" to the acoustic space in the piece, people were not aware of this, and sat facing in all directions. Most, if not all, of the acousmatic and fixed format music was packed into these noon concerts. This programming has the advantage of providing a focused set of concerts for those interested, but the weakness of overly homogenous concerts. Particularly with acousmatic music, which demands intense listening without the "entertainment" of watching a performer it was a good idea to keep the concerts under one hour. The quality of music on this concert was quite good. Since the noon concerts often were at the only break between morning and afternoon paper sessions, choices had to be made between research and music presentations if one wanted to eat lunch. (A similar choice also had to be made in whether to attend late night concerts or morning papers.) This kind of dilemma could be avoided by exercising more selectivity in programming overall.

Daniel Barreiro's (Un)folding was composed of acousmatic textures with some nice brief shrieks, and filtered long extensions going into crunchy erratic buildings. I would not have known the piece was made from paper, as the notes describe. Outside environment construction sounds went with the piece nicely at times. The piece moved into violent eruptions and tense high "suspensions," then dropped to lower frequencies. The high sounds returned in hollower timbres, then lower registers with a final crinkling. The element of unexpectedness in phrasing worked well in this piece.

Piéce de Derriére no. 2 by Volker Hennes was, according to the composer, created after analyzing a hurricane's structure. Perhaps this contributed to the integrated-ness of some of the sounds, which sounded as though they contained other sounds within them. This effective phenomenon 
occured with long noisy sounds containing punctuation, and later with high sounds containing voice-like sounds. I was reminded of gunfire at times, with bursts of around four attacks recurring as a motive near the beginning, and siren-like sounds later on. The clear sectioning and multilevel timbral construction worked well.

The third work, Robert Sazdov's Sv Kliment, made the most effective use of the eight-channel format on this concert, and was based on the composer's research in 3-D sound perception. Kliment was a scholar who probably established the first university in Europe. The piece drew on world music and vocal sounds, more traditional harmonies and repeating rhythms. I enjoyed the sounds, including some whispery/whistly/choral-like sounds, and did not perceive an attempt to create a satisfying structure. I wondered if documentary music was the compositional goal.

I enjoyed Takayuki Rai's Labyrinth the most of those I heard on this concert. The exploration of the urban landscape covered diverse timbral worlds, from jackhammer patterns revolving around the listener, dreamy wind-chime-like granular textures (which I think could have been slightly shorter), combinations of these with spatial argument, and some softer bird-like textures.
I left to set up for my presentation, and asked Daichi Ando to review the final piece, Kari Besharse's Ear to the Ground.

The real sounds - sounds of the piano performing - were very interesting. The contrasts between non-real sounds and piano sounds were a nice novelty, and filled me with curiosity. The structures of the piece were precise due to the sound constrasts. Moreover, the sounds functioned effectively with the ingenious spatialization.

\section{Wednesday, 29 August \\ 12:00-13:00, School of Architecture John ffitch}

The lunchtime concerts were openair affairs. In the middle of a circle of 8 speakers, we sat in disorganised groups to listen. For this concert there was sun, but it was rather colder than I like, so I was wrapped in coat, scarf and hat on my portable chair.

The first work was Acheron by Paul Oehlers. The program notes did not give much away about what to expect, but the six-minute piece was most enjoyable. From its start in the midst of long static-feeling sound, which developed slowly but deliberately to include bell-like highlights, there was an intense feeling of immersion in the sound. At the three-minute mark there grew more harmonic and chordal sounds, which achieved some kind of stasis before a bubbling instability took the sound to a quiet conclusion. Overall, there did not seem to be much individual spatial location of the sounds, but a unity all around. It was perhaps a little quiet overall for the outdoor location, and a light plane near the start was a little disturbing. Certainly this is a piece I would like to hear again.

The piece that followed, Friction by Chikashi Miyama, was a contrast. Reading the program notes after the concert, I learned that all the sounds came from a double bass, activated in a number of ways. My notes at the time indicate that I had in mind something falling on a violin string: The development took it to less identifiable sounds, but still within the same world. This piece made use of the 8-speake system to locate individual events around the space. The sounds were of varying amplitude and gave an overall jagged sound world. In the middle I lost the sense of development, but the introduction of longer sounds led eventually to more explicit bowed string sounds, emphasising the title and the source. The end returned to the disjoint world, and the end had what I heard as brutal bangs before dying away. I appreciated the craftsmanship of the composition, but this was not really to my taste. At 10 minutes, it seemed a little too long for the material. It is worth adding that experience has shown that my taste is not that of the majority.

The third work in the concert was not played, so we moved directly to Brian Willkie's Noche Oscura. This was a stereo work, but played through four speakers per channel. The opening of the piece featured buzzing sounds with continual variation and movement; clearly the influence of Gendy and Xenakis-like grains was to the fore. For two minutes, these sounds danced and gained in intensity before giving way to a very quiet passage. Indeed, this quiet reflective and contemplative passage was unfortunately rather too often swamped by external factors (light airplanes being the most common). The mode was broken by bangs and heavier, metallic sounds, with the buzzes now sounding menacing. Longer, steady pitched events were introduced before the bee-like sounds took us back to the mode of the opening. What a shame it was that the conditions were not right for this work. Its continuous activity within tight boundaries were

very well composed, and I want to hear this work again without the planes and other sounds.

The concert ended with another contrasting piece, Kaleidoscope: Arcade by Peter Batchelor. The conceit of the work was that it was inside a pinball machine. The sound world is of industrial sounds, broken up at times with whistles and attention-seeking bangs. The surround sound was used to give the 
illusion of the listener being inside the process. Overall, the piece worked. At times I lost the surface structure, but the unity of the sounds kept me involved for its eight and a half minutes. Apart from the introduction of long static tones at the end, the work was entertaining and engaging In fact, it was sufficiently popular with the sound crew that it was given a second playing later in the week.

The concert as a whole was enjoyable. The works contrasted with each other and used the format in different ways. My only reservation was the extraneous noises; airplanes and a police siren at times dominated the otherwise well-constructed concert.

\section{Wednesday, 29 August \\ 17:00, PLEX Music Theatre \\ by Dan Overholt and Graham Wakefield}

The concert began with Sami Klemola's Fragile, a 14-minute work commissioned by the Uusinta chamber ensemble with the support of the Sibelius Foundation. Klemola's program notes are drawn from quotations of Rene Magritte, Paul Klee, Eliel Saarinen and a Chinese proverb. The Chinese proverb informed the title of the work, with the statement "You cannot prevent the birds of sadness from passing over your head, but you can prevent their making a nest in your hair." The performance started with a pair of delicate and meditative sul ponticello bowstrokes processed and accentuated by piano motifs, followed immediately by the flute's entrance along with the ensemble. The evolving harmonies in the work consisted primarily of held sonorities connected by interjecting lines, manipulating the listener's ear with increasingly rich, busy, and complex tones. The Saarinen quote is therefore an appropriate metaphor for the harmony: "Always design a thing by considering it in its next larger context-a chair in a room, a room in a house, a house in an environment..."

Overall, the form of the work progressed into more active and frenetic lines overlaid on the harmonies. The program notes provide us with some insight into the composer's thoughts about the form through the Paul Klee quotation "Things appear in an extended and multiplied sense, often seemingly contradicting the rational experience of yesterday." Again from the program notes, the final quotation (referring to the use of computers in the work) is by Renee Magritte: "One object suggests that there is another lurking behind it." The computer-based elements of the work (at least in the performance context) consisted primarily of the processing of the sul ponticello held notes of the string section. Sparingly used, this provided an engaging, masterfully used, well executed expression of beautiful and moving sounds. A full assessment of the creative process involved in the composition of the work would have to include the detailed examination of Klemola's use of altered orchestral timbres that express quite faithfully the meaning and feeling of the work's title, Fragile.

The next work on the program was Lasso and Corral: Variations on an Ill-Formed Meter by Dan Trueman, himself performing on the Hardanger fiddle along with the Uusinta ensemble. Seven is a wonderfully uneven number, suggestively approaching crystalline eight yet naturally falling away before reaching it, emerging out of flowing mixtures of threes and fours, an obstinately asymmetric factor with a magical quality. Trueman masterfully plays with the structural rhythmic layering and sequencing of sevens throughout the various moments and sections of this composition, through an almost demonstratively presented audible click-track. Trueman himself notes the somewhat didactic quality: "at times the underlying pulses speed up and slow down, but in highly consistent, learnable ways." The Lasso in the title refers to Trueman's conception of click-track itself, "a valiant attempt to corral an out-of-control fiddle band." The pre-recorded tempo variations within the click-track were clearly anticipated in extremely fine detail by Trueman on the Hardanger fiddle, with the ensemble close behind while following along with the insistent beats. Somewhat reminiscent of other American composers such as Steve Reich, the feeling provided by the work was that of a beautiful exploration of the expressive timing inherent in the meter of 7 , dominated by sonorities implied by the unusual tuning of the Hardanger fiddle's strings to A, E, A, and C\#.

In addition to their rhythmic function in the work, the metronomic pitched pulses also construct a harmonic guide around which the ascents and descents of the fiddles gambol. On the whole, the work manages to ride out the potential traps of such a didactic or demonstrative constraint, with perhaps one exception: as the central, driving master of the work, the click track was perhaps too harsh a master. At times overstating its presence in terms of amplitude, the pulses sometimes had an aggressive quality that seemed out of keeping with the otherwise lightly musing harmonic and gestural feel. We cannot imagine that this amplitude was for the sake of the performers, who scarcely at all glanced at the visual click-tracks on their iBook screens.

Members of the "Internet generation" (if there is such a thing) may well have appreciated the next piece, Max Savikangas's Pussyhead 69. As an intermedia work, the video components were composed by Teemu Mäki, and brought to mind elements of online video sites. Many "extreme" video clips were 
organized into a patchwork of visual abandon filled with somewhat common vernacular and seemingly unnecessary hype. Despite the intention to "leave room for immersive interaction between music and video", as the musicians could also watch the screen, what appeared to come across was quite the opposite: an awkward sense of disjunction. At many points we were compelled to close our eyes in order to hear the music undistracted by the relatively ungainly rhythms of Teemu Mäki's video jockeying. Musically, the work was quite capable of standing on its own, and was well performed by the Uusinta ensemble (Savikangas is in fact a member of the ensemble). Each performer had a small display, which appeared to indicate the open form module changes to the ensemble. However, the use of effects foot-pedals produced quite audible clicks when the performers tapped them. One remarkably well-done element in the music was the effective deployment of contrasting and complementary extended techniques, showing the dichotomy between processed and non-processed sounds. Savikangas deftly juxtaposes these sounds to create what seemed, at times, to be a dueling relationship between traditional and extended techniques as well as processed and non-processed sounds.

The concert finished with Tommaso Perego's Incastro di Mondo (perhaps "tangle of the world" or perhaps "joints of the world"). Perego himself performed with the ensemble with a wireless gamepad controller. As the last paragraph of the program notes states:

Flute,Bass ClarinetandViolinareconnected to computers through microphones and are creating musical events upon some rules of a sort of a game. They listen to the electronic real-time processing on their sound, expecting unexpected and sudden changes coming from the computer. The role of the Wireless Gamepad Controller player is to provoke and manipulated the electronic responses.

The beginning of the program notes may well have put the audience in a mental state of tension before the piece even began, with phrases such as "loud and powerful metallic spheres of sound," "piercing the audience's ears," “ominous advance," and "wild forgers of violent appetites." However, the work did not offend in the slightest with such sonic atrocities. In fact, the program notes had no mention of the work's judicious use of silence, intensity of attention between musicians, details of the electronic algorithms, or the rules of the game they were playing. These are elements that were all extremely well formed in the work, no doubt due to Perego's diligence and attention to detail.

The first and second gestures in the work (and the nearly 20 seconds of silence between them) quite immediately and wonderfully switched the listener to a different state of listening. Between these gestures, a little noise from the electronic processing seemed to be leaking through the sound system. Although this could perhaps have been eliminated with a simple noise gate, it seems to us that the sonic result would not have been nearly as satisfying, and it is imagined that its absence was quite intentional. The work presented an overall diminuendo after the first minute to the end of the work (quite unusually), yet managed to hold the audience rapt. The length of the performance was just over three minutes, a perfect time in which to absorb the disparate sounds combined from the electronic processing and natural timbres. Was this a pre-composed structure, a natural output of the game rules, a result of improvisational skill, or an epiphenomenon of a different nature? Certainly the immediacy and focus of interaction between performers was quite evident and viscerally enjoyable. It was clear that the electronic processing was certainly subordinate to the performer's interaction. Perhaps the only pity, however, was that the audience was faced with Perego's back for much of the performance, only able to see his actions on the gamepad controller in the moments at which he needed to glance over to his laptop screen.

Considered as a concert event on its own, this was a show marked by a wide range of diverse compositional approaches, intermedia materials, and ambitious works. Within the scope of the entire week of ICMC 2007's wonderful programs, it showed that the assortment of works on just one concert can provide audiovisual works with enough variety to give the conference a successful and fascinating artistic focus. It was a delight to experience these works, and we will be looking forward to seeing what these composers come up with at ICMC 2008.

\section{Thursday, 30 August}

19:45, Tycho Brahe Planetarium: Omnimax dome concert

by Toine Heuvelmans

To be honest, after attending the first Planetarium video concert, I was a bit afraid of what the subject of this review might turn out to be. This, of course, had little to do with the Planetarium itself, an awesome venue for video concerts with its gigantic Omnimax dome and very comfortable seats. The Tuesday concert, however, was all but comfortable; there had been low video quality (both technically and artistically) and minimalist music (in both composition and the variety of sound material) that was often too loud. Luckily, it was rumored that this evening all the video would be HD. Although it still only filled a fraction of the entire dome, the videos did indeed turn out to be of great quality, really 
making use of the extra pixels. However let me remind you that this is all part of the International Computer MUSIC Conference, so the audience's attention should in the first place be attracted to the music and sound. A good piece in this context is one in which the music and video are of equal importance and quality, or in which the emphasis lies on the music, but the video relates to the music and is of a quality that isn't distractingly low. If you close your eyes, you still have something interesting to listen to.

The first piece, Rajmil Fischman's $i T e$ Acuerdas, hijo?, is almost the only piece in this concert that doesn't fit this description. It is as with Hollywood movies (though this work is more interesting than many of those movies) - your attention is mainly directed to the visual story and spectacle, whilst the music and sound accompany all that on a more subconscious level. The music was so supportive to the visual activity that it could hardly stand on its own if you closed your eyes. There wasn't much variety in sound character, and though this can be a virtue sometimes, it sounded more like a river of grains to me. Nonetheless, it was a pleasing piece to watch. It was well dosed, didn't numb your senses, and told a story. Visually, ¿Te Acuerdas, hijo? was of good quality. It contained some transitions, morphs and other parts (like a speaking face) that I thought were quite impressive, but this evened out with the rest of the piece to be just a nice work.

I've seen Music, When Soft Voices Die... with music by Roderik de Man and video by Marcel Wierckx once before in Holland, though it was in a relatively small room on a small screen with a lower resolution. Without the HD quality, it was already a beautiful piece both musically and visually. The composition dates from 2004, but the video was added three years later. As you might expect, then, the composition is strong enough to stand on its own. It has three chapters: first slow, then energetic tension, and then a serene ending. The sounds used are varied but do not clash, and often I couldn't distinguish right away how they were produced, which makes it more interesting. However, there's one part in which a voice utters the name of the piece (and another bit from the poem it originates from), and de Man doesn't pull this off as well as Fischman in $\dot{c}$ Te Acuerdas, hijo.; it just doesn't fit in as well. The video intentionally uses the HD standard to reach a level of detail that reflects the amount of detail in the music. It visualizes movements and moods from the composition in such a way that it increases the emotional impact, but does not distract the audience's attention from the music. The video serves more like a guideline through the composition.

The best way to explain what I find great about Elements from Jawshing Arthur Liou (video) and John Gibson (music), the third piece of the evening, is to quote Roderik de Man: "Reading programme notes at concerts, I often find that the more complicated they are, the more disappointing the piece turns out to be..." Elements had none at all. It made me think of the deterioration of a smoker. The video alternated between something that looked at first like snow but turns into ash at the end, and an extremely detailed pumping organ that turns from (almost) healthy red to black. At the end, there's a somewhat holy golden glow shining from within, perhaps representing something like recovery. This small color palette of gray, red and gold tones combined with the slow movement and very realistic 3-D animation made watching Elements an interesting experience. The slowly moving music was calming but at the same time a little frightening, complementing the video. At the end, when the golden glow occurred, a clerical voice even joined in. I wasn't bothered that the overall emphasis lay a bit too much on the visual side, because I was too much hypnotized by the combination of it all.

From one emotion into another, Dennis Miller's White Noise evoked a very strange feeling in me. It felt like peeking inside Pandora's box, or into the heart of a star nebula. Its overwhelming beauty and unreachably surrealistic complexity go hand in hand with a frighteningly chaotic destructiveness. White Noise utilized almost the same color palette as the previous piece, but there was nothing holy in this piece: hell opens right in front of you, and it's impressive!

Noise in all its forms is present in each level of both the music and the images. A constant industrial rumble is disrupted by chaotic and detailed bursts of noise, which create a well dosed but unpredictable trip through a hostile landscape of sound. Without this music, the video would be a chain of beautiful graphics, and on its own the composition is already really interesting, but the combination is extremely powerful.

Autarkeia Aggregatum by Bret Battey had a somewhat meditative musical quality, but contradicting this tranquility were the more than 11,000 points crawling around on the screen. The points moved around in a similar motion (changing from big to small circles to Brownian motion, from fast to slow movement), and were present throughout the entire piece, constantly changing color, together functioning as an organic screen. The sounds seemed to have a bit of an Indian influence, adding to the meditative character. Further into the piece, something that sounded like a reed instrument joined in, and I later read that the "natural" glissandi it played were actually generated by a tool from Battey (PICACS); it fooled me. The piece evolves and flows gradually and without cuts, making it a very relaxing piece. 
In this relaxed state the concert ended, and I left the Planetarium, satisfied that I had something worth writing about.

\section{Friday, 31 August}

\section{0:00, Queen's Hall}

by Sever Tipei

Friday's 8pm concert in Queen's Hall featured the ensemble Insomnio conducted by Ulrich Pöhl. Insomnio is a very disciplined ensemble, and the use of live electronics appears to be one of their trademarks. However, on this occasion, the amplification of the piano sometimes go out of hand. On the whole, though, they served the music very well, and there were a number of beautiful moments.

Per Bloland's Negative Mirror, Part II and Konstantin Karathanasis's Obscuritas Luminosa, Lux Obscura were the highlights of the evening. Both works are well constructed and make effective use of instruments. Although the overall results were commendable, I was left wondering if the use of the Electromagnetically Prepared Piano Device in Per Bloland's piece was really necessary from the point of view of the composition or just another gimmick.

I particularly liked Obscuritas Luminosa, Lux Obscura, which displays a refined sensuality and shows great care for detail.
Karathanasis uses a beautiful old Greek text as a subtext for his composition, which becomes an exquisite metaphor conveying a profound philosophical thought in vibrant corporeal sound images. When disregarding the motto, the music stands on its own and remains effective while nevertheless conveying a world view embedded in its minutiae.

Deep South by Lars Graugaard was the least conventionally built work on the program, with the timpani commandeering the piece at around the golden mean point and taking it into a new realm. The result is puzzling at first, and it reminded me of the morphogenetic music idea promoted two decades ago by Romanian composer Aurel Stroe. According to Stroe, some of the most interesting pieces lack stylistic unity, their formal characteristics changing during the unfolding of the work.

The other two offerings on the program were a disappointment. Dietrich Hahne's Ecoute 2

(announced in the concert booklet as NUT) incongruously pitted a rather trivial instrumental section against the speakers. Too long for the amount of the information delivered, the piece was swamped by Prokofiev-like sonorities.

The last work on the program, Mal di Luna by Calliope Tsoupaki, also wandered too long trying to highlight the virtuosity of the six-string electric cello of FrancesMarie Uitti without gaining in substance. Meant to draw attention to the genuine virtuosity of the soloist, it didn't rise above the level of a technical exercise and didn't demonstrate a justifiable need for the uncommon instrument.

A final word of praise for the sleek volume dedicated to the music programs. It is deeply regrettable that the paper schedule didn't benefit from similar attention. 